\title{
Carbohydrates intake preference among university students towards balanced intake practice
}

\author{
1,*Mohd Abd Majid, H.A., ${ }^{2}$ Ahmad Sharoni, S.K., ${ }^{1}$ Anuar, J., ${ }^{3}$ Syed Yasin, S.N. and \\ ${ }^{3}$ Raju, R. \\ ${ }^{1}$ Faculty of Hotel and Tourism Management, Universiti Teknologi MARA (UiTM), Malaysia, \\ Terengganu Branch, Dungun Campus \\ ${ }^{2}$ Faculty of Health Sciences, Universiti Teknologi MARA (UiTM), Malaysia, \\ Selangor Branch, Puncak Alam Campus \\ ${ }^{3}$ Faculty of Computer and Mathematical Science, Universiti Teknologi MARA (UiTM), Malaysia, \\ Terengganu Branch, Kuala Terengganu Campus
}

\author{
Article history: \\ Received: 10 December 2019 \\ Received in revised form: 1 \\ April 2020 \\ Accepted: 8 April 2020 \\ Available Online: 2 May \\ 2020
}

\section{Keywords:}

Malaysian food pyramid,

University students,

Food preference,

Carbohydrate

\section{DOI:}

https://doi.org/10.26656/fr.2017.4(5).403

\begin{abstract}
Food is necessary for our living since it helps in preserving our life in this world. Occasionally, we may have similar food preferences with our friends and families and sometimes we recognize the meals as the highlight for a celebration. Usually, people tend to choose their meals according to the availability of the meal in the market or the characteristics of the food itself such as the taste of the food. Students usually choose food based on their need, but it is vital for them to take care of their daily nutrient intake, especially carbohydrate $(\mathrm{CHO})$ to give them more energy to facilitate productivity and healthy daily life. However, there is a possibility to practice imbalance intake due to surrounding factors that can cause an excessive intake of nutrient which later may contribute to obesity or inadequate intake that may cause lethargic and nutrient deficiency. This study determined the carbohydrate preferences among college students in UiTM Dungun, Terengganu, Malaysia. Data collection was done by convenience sampling from 160 students (bachelor's degree student). A questionnaire that consisted of two sections; section A (socio-demographic profile) and section B (food preferences) was used to collect the data. Majority of the students chose rice $(74.4 \%)$ as their most preferred carbohydrates, followed by $10.6 \%$ noodles, $7.5 \%$ bread, $3.8 \%$ cereal product, $2.5 \%$ biscuits and only $1.3 \%$ of the students preferred tubers. This can give some ideas and more room for improvement and monitoring on the $\mathrm{CHO}$ intake towards healthy eating practice among university students. This will also help the food provider in preparing and modifying healthy meal according to food preferences at the university's cafeteria. In addition, this may also assist food manufacturer to get some ideas for proposing healthier food innovation in the future based on youth preference.
\end{abstract}

\section{Introduction}

Carbohydrate (CHO) consumption can provide energy to our body and it is a fundamental part of the human diet all over the world. Principally, a diet with high consumption of carbohydrates (except sugar) associates with the high nutritional quality of the diet. The sources for carbohydrate include rice, grains, cereal, fruit, vegetables, dairy products as well as the sugar starch and fiber (Mahan et al., 2012). It is critical to differentiate carbohydrate and oils or fat since carbohydrate is less calorific.
Das et al. (2017) stated that adolescent is where the period of rapid growth occurs. Thus, to accomplish full growth potential among adolescent, sufficient energy and nutrition intake is vital. It is essential to meet the nutritional requirement in sustaining optimal health and to decrease the threat of diseases. Macronutrients such as carbohydrate, fat and protein are required in large amount, as compared to micronutrients that are required only in a very small amount (IPH, 2017). According to the Recommendation Nutrient intake (RNI) for Malaysia 2017, it has recommended that total daily energy intake (TEI) from carbohydrate should be between 50-65\%. (NCCFN, 2017). Previously, according to the National 
Health Morbidity survey among adolescent, it showed that $51.5 \%(95 \%$ CI: $48.89,55.94)$ of the adolescents has met the recommendation. Only $4.4 \%$ (95\% CI: 2.97 , 5.32 ) surpassed the limit which consumes more than $65 \%$ of the TEI. However, $44.1 \%$ (95\% CI: $40.00,47.26$ ) of the adolescents consume carbohydrate below the recommendation limit (<50\%) (IPH, 2017).

Food preference develops since before birth and may change as one aged (Hale, 2018). There are several factors contributing to food preference such as physical, biological, society and culture. It differs between people and these factors will affect food preference pattern during breakfast, lunch, hi-tea, dinner and supper (Vabø and Hansen, 2014). Nowadays, students always have a busy schedule and they are the only one responsible for their own health. It is vital for them to take care of their daily nutrient intake, especially carbohydrate to give them more energy to facilitate productivity and healthy daily life. It is vital for them to take care of their daily nutrient intake, especially carbohydrate to give them more energy to facilitate productivity and healthy daily life. However, there is a possibility to practice imbalance intake due to surrounding factors that can cause an excessive intake of nutrient which later may contribute to obesity or inadequate intake that may cause lethargic and nutrient deficiency. They are also exposed to morbidities if they do not take any precaution from this related issue.

In recent times, the improvement in technology and increased healthy eating concern among the society had encouraged the food manufacturers to create wholesome meals related to carbohydrate. Through this approach, it can inspire and encourage society to consume wholesome foods and have a healthy lifestyle. Few studies had been done on innovative bread development due to the increase in obesity problems in society (Blažeková et al., 2015). In step with the study, few scholars also developed wholesome food such as food rich in fiber and beta-glucan by adding oat into the sourdough, which will be applied to produce oat bread that is healthier for the weight loss plan. Besides, the fermented oat sourdough can also be used in manufacturing the bakery products instead of evolution for healthy foods only (Blažeková et al., 2015).

Currently, few carbohydrate food innovations had been generated in Malaysia, particularly for bread like bran and wheat germ, wholegrain and fine grain whole meal. Wholegrain bread had been one of the revolutionary bread that was made from wholegrain and supply important nutrient for a healthy body. In line with the studies, whole grains are one of the food groups that prevent the possibility of diabetes type 2 disease as well as heart disease (Kyrø et al., 2018). Hence, individuals who seek to maintain a healthy body are recommended to consume healthy carbohydrate food sources like wholesome meals as one of the alternatives. Therefore, this study aims to determine carbohydrate preferences among college students in UiTM Dungun, Terengganu. This is important to see one's preference that may help them achieve balance carbohydrate intake and assist food manufacturer to develop some ideas towards more healthy food choices based on youth preference.

\section{Materials and methods}

This study is a descriptive study involving 160 students who were recruited by convenience sampling from all faculties in Universiti Teknologi MARA (UiTM) Dungun Campus, Terengganu, Malaysia. This study aimed to evaluate the carbohydrate choices among the students who were different in ages, genders and diverse programs such as Bachelor of Finance, Bachelor of Hotel Management and Bachelor of Food Service. For the data collection, a questionnaire was adapted from Food Frequency Questions (FFQ) from National Health and Nutrition Examination Survey, (NHANES) (CDC, NCHS, 2015) as well as from Harvard Food Frequency Questionnaire (HSPH, 2012). The questionnaire was distributed to the participants, consisting section A (socio -demographic profile) and section B (food preferences). The food preferences part compromised the questions regarding food in the carbohydrate groups such as rice, noodles, bread, cereal product, biscuits and tubers. Each group consists of six dimensions questionnaire that needs to be answered by the respondents (i.e., the most preferred food in each type of group, the most preferred way of consumption, the most preferred place to buy food/dishes and the frequency of the food being taken). Section A was multiple-choice questions. Meanwhile, for Section B, there were multiple-choice, short questions and a 'yes' or 'no' questions. All questions are required to be answered by the participants for them to move to another section in this questionnaire. The questionnaire was prepared in multi-language; Malay and English for a better understanding and had been validated in a pilot study. Cronbach's Alpha ranging from 0.62 to 0.70 was reported in the pilot study and was acceptable in the study (Nunnally, 1994). The questionnaire was handed to the focus group of respondents, based on the time and suitability of respondents, which has been arranged beforehand. The instructions of the questionnaire were explained to the respondents and were collected on the same day. Respondents finished answering the question in 15 to 30 minutes. Social package for Social Sciences (SPSS) model version 20.0 was used to analyze the data. Descriptive statistics were carried out to determine the food preferences of the respondents. 


\section{Results}

\subsection{Socio-demographic}

Figure 1 shows the socio-demographic data of this study. From the result, 160 university students participated in this study with the majority were female $(87.5 \%, n=140)$ and only $12.5 \%(n=20)$ were male. It was also found that most of the respondents were aged between 18 to 20 years $(83.7 \%, \mathrm{n}=134)$ and followed by respondents aged between 20 to 25 years old with $16.3 \%$ $(\mathrm{n}=26)$.

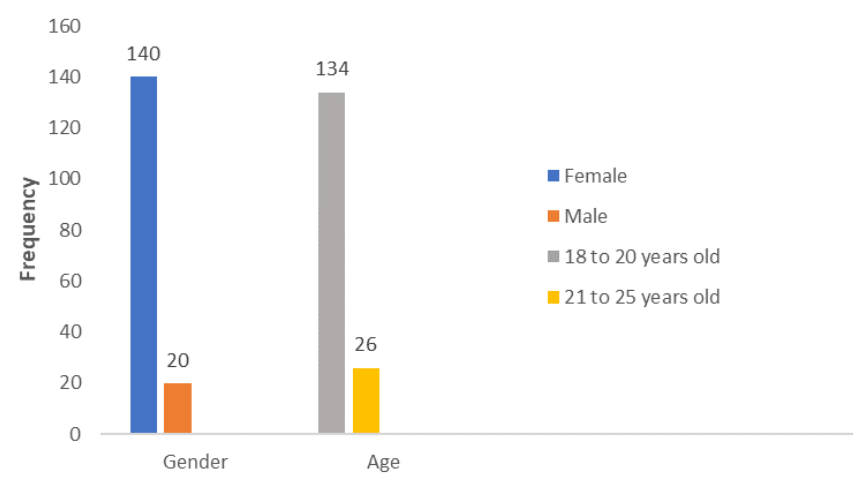

Figure 1. Socio-demographic data of respondent (Frequency)

\subsection{Type of carbohydrate preferences among students}

Carbohydrate preference among respondents was divided into six groups: rice, noodles, bread, cereal product, biscuits and tubers. In general, rice was the most preferred carbohydrate with a score of $74.4 \% \quad(n=119)$ while $10.6 \%(n=17)$ of the respondents chose noodles (Figure 2). Meanwhile, bread was the third $(7.5 \%, n=12)$ most chosen in the carbohydrate group. This study also found that only $3.8 \%(n=6)$ respondents chose cereal products while the least chosen carbohydrates were tubers $1.3 \%(\mathrm{n}=2)$ followed by biscuits $2.5 \% \quad(\mathrm{n}=4)$. Therefore, this study showed that rice was the most chosen carbohydrates while the least chosen carbohydrates were tubers.

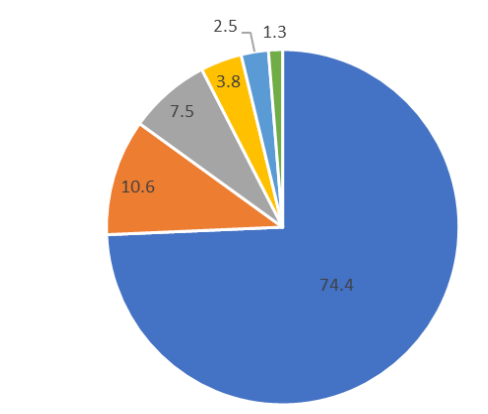

- Rice $\quad$ - Noodles $=$ Breads $\mid$ Cereal products $\quad$ Biscuits $\quad$ - Tubers

Figure 2. Carbohydrate preference among respondents (\%)

\subsubsection{Rice}

Table 1 shows the frequency and percentage of respondent preferring rice. White rice was the most preferred type of food with a score of $89.4 \%(\mathrm{n}=143)$. Then, it was found that $8.1 \%(n=13)$ of the respondents preferred glutinous rice, followed by $1.9 \%(n=3)$ chose brown rice and lastly was other type of rice such as Japanese rice. According to the result, frying method was the most preferred way to consume by the respondents with a score of $52.5 \%(n=84)$ and the food prepared included fried rice. Then, $23.8 \% \quad(n=38)$ of the respondents chose steaming which included steamed rice. Meanwhile, boiling was the third preferred by respondents with $16.3 \%(n=26)$ and the example of the food cooked by using the boiling method is porridge. It was reported that most of the respondents, $55.6 \%(n=89)$ prefer to buy the rice at the cafeteria, followed by supermarket $17.5 \% \quad(\mathrm{n}=28)$. Meanwhile, the least preferred place to buy food by the respondents was convenient stores $(1.3 \%, \mathrm{n}=2)$. Other places like night market or roadside stalls scored as second least preferred by respondents $(12.5 \%, \mathrm{n}=20)$. There were also respondents who bought the rice at groceries with a score of $13.1 \%(n=21)$. As shown in the table, $28.8 \%(n=46)$ of the students consumed rice once per day. Then, it was found that $24.2 \%(n=39)$ of respondents consumed rice 2 to 3 times per day, followed by 2 to 3 times weekly with a percentage of $19.4 \quad(n=31)$. The frequency and percentage of students that consumed rice 4 times per week is $16.9 \%(n=27)$ and only $1.3 \%(n=2)$ of the respondents consumed 4 or more times rice per day.

Table 1. Frequency and percentage of respondent preferring rice $(\mathrm{N}=160)$

\begin{tabular}{lcc}
\hline $\begin{array}{l}\text { The Most Preferred Food in } \\
\text { Each Type of Group }\end{array}$ & Frequency & $\begin{array}{c}\text { Percentage } \\
(\%)\end{array}$ \\
\hline White rice & 143 & 89.4 \\
Glutinous rice & 13 & 8.1 \\
Brown rice & 3 & 1.9 \\
Other (e.g. Japanese rice) & 1 & 0.6 \\
\hline \multicolumn{3}{l}{ The Most Preferred Way of Consumption } \\
\hline Frying (e.g. fried rice) & 84 & 52.5 \\
Steam (e.g. nasi kukus) & 38 & 23.8 \\
Boiling (e.g. porridge) & 26 & 16.3 \\
Other (e.g. nasi lemak) & 12 & 7.5 \\
\hline The Most Preferred Place to Buy Food/Dishes & \\
\hline Cafeteria & 89 & 55.6 \\
Supermarkets & 28 & 17.5 \\
Groceries & 21 & 13.1 \\
Other (e.g.night market) & 20 & 12.5 \\
Convenient store & 2 & 1.3 \\
\hline Frequency of The Food Being Taken & \\
\hline 1 time per day & 46 & 28.8 \\
2-3 times per day & 39 & 24.4 \\
2-3 times per week & 31 & 19.4 \\
4 times per week & 27 & 16.9 \\
1 time per week & 15 & 9.4 \\
4 or more times per day & 2 & 1.3 \\
\hline
\end{tabular}




\subsubsection{Noodles}

Table 2 depicts kuey teow as the most preferred food in the noodle's category with $35 \%(n=56)$ chose it. Then, the second preferred food in this category with only 1 vote different with kuey teow was vermicelli with a percentage of $34.4(\mathrm{n}=55)$, followed by yellow noodle with a score of $18.1 \%(n=29)$. The least preferred noodle type was pasta with only $12.5 \%(n=20)$. Meanwhile, for the most preferred way to consume noodle, boiling was the most preferred with a score of $57.5 \%(n=92)$ and the examples of food included noodles soup and tom yam. The second most preferred way to consume noodle was frying with a score of $35 \%(n=56)$ like fried noodles. The results followed by other preference of eating noodle $6.9 \%(n=11)$ such as instant noodles and the least preferred way to eat noodles was steaming $(0.6 \%, n=1)$ like laksam. As depicted in the table, most of the respondents $(53.1 \%, \mathrm{n}=85)$ chose the cafeteria, followed by other places such as the night market with a score of $16.3 \%(n=26)$ to buy noodles. Then, $15.6 \%(n=25)$ of the respondents chose groceries; followed by $12.5 \%(\mathrm{n}=20)$ respondents chose supermarkets and the least was convenient stores with $2.5 \%(n=4)$. Table 2 also shows the frequency of the noodle being consumed. The percentage of respondents that consumed noodles once a week and 2 to 3 times per week were similar, which is $41.3 \%(n=66)$. This was followed by consumption of 4 times per week $(10.6 \%, n=17)$ and once per day $(4.4 \%$, $\mathrm{n}=7$ ). Then, the least frequency of noodles consumption was 2 to 3 times per day and 4 or more times per day with a score of $1.3 \%(n=2)$.

Table 2. Frequency and percentage of respondent preferring noodles $(\mathrm{N}=160)$

\begin{tabular}{lcc}
\hline $\begin{array}{l}\text { The Most Preferred Food in } \\
\text { Each Type of Group }\end{array}$ & Frequency & $\begin{array}{c}\text { Percentage } \\
(\%)\end{array}$ \\
\hline Kuey teow & 56 & 35.0 \\
Bihun & 55 & 34.4 \\
Yellow mee & 29 & 18.1 \\
Pasta & 20 & 12.5 \\
\hline The Most Preferred Way of Consumption & \\
\hline Boiling (e.g. soup noodles) & 92 & 57.5 \\
Frying (e.g. fried noodles) & 56 & 35 \\
Other (e.g. instant noodles) & 11 & 6.9 \\
Steam (e.g. laksam) & 1 & 0.6 \\
\hline The Most Preferred Place to Buy Food/Dishes & \\
\hline Cafeteria & 85 & 53.1 \\
Supermarkets & 26 & 16.3 \\
Groceries & 25 & 15.6 \\
Other (e.g.night market) & 20 & 12.5 \\
Convenient store & 4 & 2.5 \\
\hline Frequency of The Food Being Taken & \\
\hline 1 time per week & 66 & 41.3 \\
2-3 times per week & 66 & 41.3 \\
4 times per week & 17 & 10.6 \\
1 time per day & 7 & 4.4 \\
2-3 times per day & 2 & 1.3 \\
4 or more times per day & 2 & 1.3 \\
\hline
\end{tabular}

eISSN: 2550-2166

\subsubsection{Bread}

Table 3 depicts the frequency and percentage of respondent preferring bread. The current study found that white sandwiches were the most chosen bread among the respondents with a score of $51.3 \% \quad(n=82)$. Then, followed by flavoured bread (chocolate and corn flavoured) with $33.1 \%(n=53)$. Apart from that, the wholemeal bread was in the third-highest place with a percentage of $15.0 \%(n=24)$ and the least preferred was another type of bread (biscuit bread) with a result of $0.6 \%(n=1)$. It was reported that the sandwich was the most preferred dishes chosen by the respondents with a score of $20.6 \%(n=33)$, as shown in Table 3. Egg toast was the second preferred meals in bread category $(16.9 \%, \mathrm{n}=27)$, followed by other dishes such as roti pau $(12.5 \%, \mathrm{n}=20)$ and plain bread toast $(11.9 \%, \mathrm{n}=19)$. The finding also showed that the least chosen meal from bread was roti canai and cheese bread with a score of $1.3 \%(\mathrm{n}=2)$ respectively, followed by vanilla bread $(1.9 \%, n=3)$. In the category of bread, the table also illustrates the most preferred place chosen by respondents to buy the bread products. Groceries were the most preferred with $30.0 \%(n=48)$ followed by the supermarket with $26.9 \%(n=43)$. The third-place chosen by the respondents with a score of $19.4 \%(n=31)$ was the cafeteria, followed by convenient stores $(14.4 \%, n=23)$. The least preferred was the bakery shops, which is $9.4 \%$ $(n=15)$. For the bread category, according to Table 3 majority of the respondents consumed bread 2 to 3 times in a week with a score of $42.5 \%(n=68)$. Then, the second-highest frequency of bread consumption was once per week $(31.9 \%, \mathrm{n}=51)$, the third-highest was 4 times per week $(13.1 \%, \mathrm{n}=21)$ followed by once per day $(9.4 \%, \mathrm{n}=15)$ and 2 to 3 times per day $(2.5 \%, \mathrm{n}=4)$. Meanwhile, the least frequency of bread consumed by the respondents was 4 or more times per day with $0.6 \%$ $(n=1)$.

\subsubsection{Cereals products}

Table 4 shows the frequency and percentage of respondent preferring cereals products. Generally, cold cereal had higher demand among respondents with $75.6 \%(n=121)$ while $21.3 \%(n=34)$ of the respondents chose hot cereal. Cornflakes were the least preferred $(3.1 \%, n=5)$. Referring to the most preferred way it is consumed, almost half of the respondents preferred to consume cereal with milk, which is $46.9 \%(n=75)$, followed by oatmeal with $20.0 \%(n=32)$. They are followed by other cereal selection (as ice cream topping, popia nestum, and etc), $17.5 \%(\mathrm{n}=28)$, nestum $(8.1 \%$ $\mathrm{n}=13)$ oat with yogurt $(5.6 \% \mathrm{n}=9)$ and only $1.9 \%(\mathrm{n}=3)$ had oat with Milo. According to Table 4, the supermarket was the best place chosen by the 
Table 3. Frequency and percentage of respondent preferring breads $(\mathrm{N}=160)$

\begin{tabular}{|c|c|c|}
\hline The Most Preferred Food in Each Type of Group & Frequency & Percentage $(\%)$ \\
\hline White sandwich & 82 & 51.3 \\
\hline Flavoured (e.g. chocolate and corn flavoured) & 53 & 33.1 \\
\hline Wholemeal & 24 & 15 \\
\hline Other (e.g. biscuit bread) & 1 & 0.6 \\
\hline \multicolumn{3}{|l|}{ The Most Preferred Way of Consumption } \\
\hline Sandwich (e.g. meat, tuna and chicken) & 33 & 20.6 \\
\hline Egg toast & 27 & 16.9 \\
\hline Other (e.g.pau) & 20 & 12.5 \\
\hline Plain bread toast & 19 & 11.9 \\
\hline Plain bread & 13 & 8.1 \\
\hline Spreaded bread & 12 & 7.5 \\
\hline Tuna bun & 11 & 6.9 \\
\hline Corn bread & 10 & 6.3 \\
\hline Sausage bread & 8 & 5 \\
\hline Vanilla & 3 & 1.9 \\
\hline Roti canai & 2 & 1.3 \\
\hline Cheese bread & 2 & 1.3 \\
\hline \multicolumn{3}{|l|}{ The Most Preferred Place to Buy Food/Dishes } \\
\hline Groceries & 48 & 30 \\
\hline Supermarkets & 43 & 26.9 \\
\hline Cafeteria & 31 & 19.4 \\
\hline Convenient store & 23 & 14.4 \\
\hline Other (e.g. bakery shop) & 15 & 9.4 \\
\hline \multicolumn{3}{|l|}{ Frequency of The Food Being Taken } \\
\hline 2-3 times per week & 68 & 42.5 \\
\hline 1 time per week & 51 & 31.9 \\
\hline 4 times per week & 21 & 13.1 \\
\hline 1 time per day & 15 & 9.4 \\
\hline 2-3 times per day & 4 & 2.5 \\
\hline 4 or more times per day & 1 & 0.6 \\
\hline
\end{tabular}

Table 4. Frequency and percentage of respondent preferring cereal products $(\mathrm{N}=160)$

\begin{tabular}{lcc}
\hline The Most Preferred Food in Each Type of Group & Frequency & Percentage (\%) \\
\hline Cold & 121 & 75.6 \\
Hot & 34 & 21.3 \\
Other ( e.g. cornflake) & 5 & 3.1 \\
\hline The Most Preferred Way of Consumption & & \\
\hline Cereal with milk & 75 & 46.9 \\
Oatmeal & 32 & 20 \\
Other (e.g. cereal topping and popia nestum) & 28 & 17.5 \\
Nestum & 13 & 8.1 \\
Oat with yogurt & 9 & 5.6 \\
Oat with milo & 3 & 1.9 \\
\hline The Most Preferred Place to Buy Food/Dishes & & \\
\hline Supermarkets & 109 & 20 \\
Groceries & 32 & 5 \\
Convenient store & 8 & 4.4 \\
Cafeteria & 7 & 2.5 \\
Other ( e.g. online purchase) & 4 & \\
\hline Frequency of The Food Being Taken & & 50 \\
\hline 1 time per week & 80 & 32.5 \\
2-3 times per week & 52 & 9.4 \\
4 times per week & 15 & 7.5 \\
1 time per day & 12 & 0.6 \\
2-3 times per day & 1 & 0 \\
4 or more times per day & 0 & (1) \\
\hline
\end{tabular}


respondents to buy cereal products, which is $68.1 \%$ $(n=109)$ while groceries were ranked second with $20.0 \%$ $(\mathrm{n}=32)$. This was followed by convenient stores and cafeteria with results of $5.0 \%(n=8)$ and $4.4 \%(n=7)$ respectively. The rest reported other such as from online purchase with $2.5 \%(n=4)$. Apart from that, for the frequency of respondents that consumed cereal products about $50.0 \%(\mathrm{n}=80)$ of the respondents had it once a week, while $32.5 \%(n=52)$ consumed 2 to 3 times per week and 9.4\% $(\mathrm{n}=15)$ consumed 4 times per week. Besides, the results also reported that only $7.5 \%(n=12)$ of the respondents ate cereal product once per day. The least frequency was 2 to 3 times per day $0.6 \%(n=1)$.

\subsubsection{Biscuits}

Table 5 shows that wafer rolls are the most preferred types of biscuits among students with $45.0 \%(n=72)$. Crackers dominated the second most preferred biscuit, with $43.8 \%(n=70)$ followed by cream biscuits $10.0 \%$ $(\mathrm{n}=16)$. The least favourite among students with $1.3 \%$ $(n=2)$ was the other category of biscuits like biscuit bread. Meanwhile, it was found that the most preferred way to consume biscuit products was flavoured-biscuit with $53.0 \%(n=85)$ and cracker with $26.3 \%(n=42)$, as the second higher preferred biscuit. Then, it was followed by other preference (taken with milk, coffee and tea), $13.1 \%(\mathrm{n}=21)$, sandwich biscuits, 3.8\% ( $\mathrm{n}-6)$, and cookies with $2.5 \%(n=4)$. Meanwhile, wholemeal biscuits were the least preferred with a score of $1.3 \%$ $(n=2)$. Table 5 also shows the place preferences to find biscuit products, reported in frequency and percentage. It was reported that the most favourable place selected by the respondents was the supermarket with $49.4 \%(n=79)$. Then, the second favourable to purchase the products was groceries with $39.4 \% \quad(n=63)$ followed by convenient stores with $6.9 \%(n=11)$. The current study also found that other places like the bakery shop got the least preference with $0.6 \%(\mathrm{n}=1)$ and followed by cafeteria $(3.8 \%, n=6)$. The highest frequency of biscuits consumption was 2-3 times per week which is $34.4 \%$ $(\mathrm{n}=55)$, followed by once in a week, 4 times per week and once per day with a score of $32.5 \%(n=52), 13.8 \%$ $(n=22)$, and $10.6 \% \quad(n=17)$ respectively. The least frequency of consumption was 4 or more times per day and 2 to 3 times per day with a similar result of $4.4 \%$ $(n=7)$.

\subsubsection{Tubers}

Table 6 reports the frequency and percentage of respondent preferring tubers. It was found that potato was the most preferred with a score of $74.4 \%(n=119)$, followed by tapioca with the percentage of $16.9 \%(n=27)$ and yam $5.0 \%(\mathrm{n}=8)$ as the third most favourite tubers. Chinese potato and sweet potato, categorized as others, were the least preferred with a score of $3.8 \%(n=6)$. For the preference of way it being consumed, the majority of

Table 5. Frequency and percentage of respondent preferring biscuits $(\mathrm{N}=160)$

\begin{tabular}{lcc}
\hline The Most Preferred Food in Each Type of Group & Frequency & Percentage (\%) \\
\hline Wafer rolls & 72 & 45 \\
Crackers & 70 & 43.8 \\
Creams & 16 & 10 \\
Other (e.g. biscuit bread) & 2 & 1.3 \\
\hline The Most Preferred Way of Consumption & & \\
\hline Flavours & 85 & 53 \\
Crackers or no flavors & 42 & 26.3 \\
Other (e.g. with milk, coffee and tea) & 21 & 13.1 \\
Sandwich biscuits & 6 & 3.8 \\
Cookies & 4 & 2.5 \\
Wholemeal biscuits & 2 & 1.3 \\
\hline The Most Preferred Place to Buy Food/Dishes & & \\
\hline Supermarkets & 79 & 49.4 \\
Groceries & 63 & 39.4 \\
Convenient store & 11 & 6.9 \\
Cafeteria & 6 & 3.8 \\
Other (e.g. bakery shop) & 1 & 0.6 \\
\hline Frequency of The Food Being Taken & & \\
\hline 2-3 times per week & 55 & 34.4 \\
1 time per week & 52 & 32.5 \\
4 times per week & 22 & 13.8 \\
1 time per day & 17 & 10.6 \\
2-3 times per day & 7 & 4.4 \\
4 or more times per day & 7 & 4.4 \\
\hline
\end{tabular}


Table 6. Frequency and percentage of respondent preferring tubers $(\mathrm{N}=160)$

\begin{tabular}{lcc}
\hline \multicolumn{1}{c}{ The Most Preferred Food in Each Type of Group } & Frequency & Percentage (\%) \\
\hline Potato & 119 & 74.4 \\
Tapioca & 27 & 16.9 \\
Yam & 8 & 5 \\
Other (e.g. Chinese potato and sweet potato) & 6 & 3.8 \\
\hline The Most Preferred Way of Consumption & & \\
\hline Frying & 69 & 43.1 \\
Boiled & 58 & 36.3 \\
Other (e.g. steam) & 21 & 13.1 \\
Baked & 12 & 7.5 \\
\hline The Most Preferred Place to Buy Food/Dishes & & \\
Supermarkets & 57 & 35.6 \\
Other (e.g. fresh, morning and night market) & 40 & 25 \\
Groceries & 38 & 23.8 \\
Cafeteria & 24 & 15 \\
Convenient store & 1 & 0.6 \\
\hline Frequency of The Food Being Taken & & \\
1 time per week & 111 & 69.4 \\
2-3 times per week & 30 & 18.8 \\
4 times per week & 11 & 6.9 \\
2-3 times per day & 4 & 2.5 \\
1 time per day & 3 & 1.9 \\
4 or more times per day & 1 & 0.6 \\
\hline
\end{tabular}

the respondents chose the frying method with a score of $43.1 \%(n=69)$. The second preferred was boiling dishes $(36.3 \%, \mathrm{n}=58)$. Steam, categorized as others, was the second least preferred way to consume followed by baking with $7.5 \%(n=12)$. The finding of the current study found that the majority of the respondents purchased the tuber products at the supermarket with a result of $35.6 \%(n=57)$, followed by other places like fresh market, morning market and night market with the score of $25.0 \%(n=40)$. Groceries were the third place that the respondents preferred with $23.8 \%(n=38)$ while the fourth place was the cafeteria $15.0 \% \quad(n=24)$. Meanwhile, the convenient store was the least preferred place with a score of $0.6 \%(n=1)$. This study also found that the majority of the respondents $(69.4 \%, n=111)$ consumed tuber dishes once per week. Respondent $(18.8 \%, \mathrm{n}=30)$ consumed tubers 2 to 3 times per week. Besides, there were also $6.9 \%(n=11)$ and $2.5 \%(n=4)$ of the respondents consumed tuber products 4 times in a week and 2 to 3 times daily respectively. The least consumption of tuber products was 4 or more times per day with $0.6 \%(\mathrm{n}=1)$ followed by once per day, $1.9 \%$ $(n=3)$.

\section{Discussion}

\subsection{Carbohydrate preference}

In this study, the preference of students toward rice was higher than other carbohydrate groups. This is similar to the study done by Supakornchuwong and Suwannaporn (2012). The study reported that compared to pasta and potatoes, rice was the most chosen among majorities of French, Dutch, Belgian and British citizens. This may be due to its taste, low in calorie and give health benefits. Besides, rice also has been known as a staple food in Asian as well as Malaysia, causing it to be the most selected among the consumers (Musa et al., 2011). Furthermore, in a study by Khor (2012), rice was regularly consumed by Malay rural household, along with other food which are anchovies and marine fish. Rice is one of the sources of carbohydrate which is important to provide energy to the body. Rice has been the primary source of calories for the people. For most of the population in the world, especially Asian countries such as Malaysia, rice stood as a staple food for a living (FAO, 2004). Hence in many regions of the world rice is commonly consumed daily, to meet the nutritional requirement of millions of people, as it is the main source of calories (Fathima et al., 2017).

\subsection{Rice}

The most common type of rice is white rice and was chosen by most of the respondents. According to the data by Harun et al. (2018), most of the respondents consumed white rice in their daily diets, while brown rice was the least consumed by the respondent. Due to its higher price and unfamiliar taste compared to white rice, brown rice was less preferred. Nevertheless, there were some respondents chose brown rice due to its nutrient and quality content that provide more health benefits. Comparing to the white rice, brown rice is a low glycaemic index (GI) food. In this way, patients that are 
vulnerable to type II diabetes are encouraged to consume brown rice (Rohman et al., 2014).

From the data, most of the students consumed rice once per day, indicating that they chose rice as their necessary food as well as an energy source for them. Besides, in a study that reviewed the customers' attitudes, it was reported that the respondents were generally purchasing rice once a day. The data is complementary to the Malaysian dietary guidelines that suggested the societies to consume a reasonable amount of rice. Thus, it depicts that most students eat rice once a day. Some of the respondents were concerned about their health, thus they tend to not consume rice more than 1 time per day.

The consumer usually tends to choose the best quality food that is affordable. This can be supported by Hanis et al. (2012) as cited in Harun et al. (2018), where high-quality rice has been demanded by Malaysians due to changes in their lifestyles. This shows that Malaysians are significantly shifting their perception of healthy products. However, according to a study by Ogundele (2014), socio-demographic and physical factors such as level of education, age, family status, gender, and profession largely influenced the preference of local rice.

\subsection{Noodles}

Noodle is one of the components in the carbohydrate group. According to Eddyono and Subroto (2014), the government of Indonesia has started the development of healthful meals consumption program, which encouraged their citizens to pick noodles as their primary menu. Based on the questionnaire, noodle is the second carbohydrate food that has been chosen by the respondents. It is a type of food that is mostly consumed by all ranges of age, due to its reasonable price and easy to prepare (Keyimu, 2013). Out of all the noodles, kuey teow was the most preferable, mostly by boiling and frying method of cooking. kuey teow is a type of rice noodles that usually cooked by frying and mixed with sauce or chilli paste (Thomas et al., 2014).

\subsection{Bread}

Bread is the third preferable carbohydrate group in this study. Although the respondents mostly choose rice, it was found that there was few of them chose bread and wheat instead of rice due to the growth of urbanization nowadays. There is a noteworthy adaptation in dietary energy in Malaysia in terms of the food source. It appears that Malaysians diet patterns are more towards wheat-meat-oil-fat-sugar-based diets, thus shows an increase in wheat preference among them (Soon and Tee, 2014). Malaysian people like to consume bread as a snack especially during breakfast. Nevertheless, Malaysians still need to take rice at least once a day to provide extra energy to do daily activities because bread is not a staple food for Malaysians.

\subsection{Cereal products}

The finding shows that most of the college students do not like to take cereal products as their main meal. According to some researchers, oat or grains consumption were still lower for many countries. Thus, the government must take actions such as policies implementations, monitoring and evaluation of nutrition habits to encourage and engage people to choose a healthy diet (Mozaffarian et al., 2018). There was only $22 \%$ of children, specifically, school children in Kuala Lumpur that consumed breakfast daily and the factors that may lead to the consumption of cereal with milk included the availability, convenience and the best way to consume the food (Hui-Chin et al., 2015). Besides, for university students, it was recommended to increase their nutritional knowledge to increase a healthy eating habit (Halim and Mohd Yusof, 2017).

\subsection{Biscuits}

In a previous study on the food consumption pattern among Malaysian adults, it was reported that biscuit was in the list of the most consumed food daily among the age group. Besides, the idea from the manufacturer, which is using the small convenience packaging, had help in promoting people to consume biscuits. Cracker is the second-highest preference among youth. According to Neo et al. (2007), as cited in Norhayati et al. (2015), crackers are solely preferred by Malaysian consumers due to its unsweetened, crispy, salty, creamy and thin characteristic, which remarkably increase the sales of biscuit in Malaysia.

\subsection{Tubers}

The data shows that tubers are the least chosen by the respondents. However, the intake of potato is expected to increase in the future, as Malaysians tend to follow the western trend. Rapid nutrition transition in developing countries is mainly caused by globalization, which subsequently increments the number of Western fast-food franchises and supermarkets (Lipoeto et al., 2013). This shows that people nowadays are attracted to western food. Meanwhile, the substantial items sold at western fast-food restaurants are fried food commonly potato French fries (Cahill et al., 2014). Hence, the increasing number of fast-food consumption as well as unhealthy food choices was due to the availability and accessibility of fast-food restaurants (Abdull Hakim et al., 2012). It was found that the majority of the 
respondents consumed fried food daily. Potato chips and French fries, types of food derived from tubers, were commonly consumed among fried products, supported with the result of this study. However, continuous fried food consumption is not advisable as it may lead to various health risks.

Regarding the data, most respondents chose to buy food at the cafeteria and supermarket. Based on a study by Lateef et al. (2016), most respondents chose to have outside food instead of cooking it themselves. This matter may be due to regulations in college that cooking is prohibited. Therefore, the nearest place that they were able to access the food was the cafeteria. Cafeteria probably serves more varieties of food at cheaper prices than restaurants or a fast-food franchise. The availability of the food supplied in the store might attract the customer to purchase the meal at the outlet (Hawkins and Mothersbaugh, 2010). Musa et al. (2011) stated that the factors affected the choice of place to purchase the food were food accessibility, including the distance of the store with their house or college. Based on a study by Gan et al. (2011), as cited in Lateef et al. (2016) most of the university students in Malaysia choose food according to the price and availability. This may be worrisome since their healthy eating pattern will be changed.

\section{Conclusion}

In summary, the study shows the top preference for each of the food in carbohydrate according to the most preferred food in each type of group, the most preferred way of consumption, the most preferred place to buy food/dishes and the frequency of the food being taken. Rice was the most preferred carbohydrate and it was due to its role as the staple food for the Malaysians, in comparison with biscuits, bread, cereal products, tubers and noodles. Frying was the most preferable cooking method for rice chosen by the respondents. Besides, most of the student had chosen cafeteria as the most preferred place to find the rice and the majority of the respondents consumed rice 1 time per day. Therefore, the current study has increased the information regarding food preference among university students. Some of the contributors to these results were due to the types of food sold at the food stalls or cafeteria inside or outside the university as well as food prices. Hence, for future study, it is recommended to widen the study to all youth in Malaysia to see the big picture of food preferences that may support balance intake of carbohydrate and healthy eating practices among youth in Malaysia. This can give some ideas and more room for monitoring healthy eating practice among university students. This will also help the food provider in preparing and modifying healthy meal according to food preferences at the university's cafeteria. In addition, this may also assist food manufacturer to get some strategies for developing healthier food innovation in the future based on youth preference. This simultaneously may spread a big spectrum for food providers and manufacturers to sell and develop healthy food choices for the students to improve their health and avoid health problems or diseases in future.

\section{Conflict of interest}

The authors declare no conflict of interest.

\section{Acknowledgments}

This research is collaboration between Universiti Teknologi MARA and Nutrition Centre of Health Department, Dungun, Terengganu, Malaysia. Special thanks for the great support throughout all this study.

\section{References}

Abdull Hakim, N.H., Muniandy, N.D. and Danish, A. (2012) Nutritional status and eating practices among university students in selected universities in Selangor, Malaysia. Asian Journal of Clinical Nutrition, 4(3), 77-87. https://doi.org/10.3923/ ajcn.2012.77.87

Blažeková, L., Polakovičová, P., Mikušová, L., Kukurova, K., Saxa, V., Ciesarova, Z. and Šturdík, E. (2015). Development of innovative health beneficial bread using a fermented fibre-glucan product. Czech Journal of Food Sciences, 33(2), 118 -125. https://doi.org/10.17221/42/2014-CJFS

Cahill, L.E., Pan, A., Chiuve, S.E., Sun, Q., Willett, W. C., Hu, F.B. and Rimm, E.B. (2014). Fried-food consumption and risk of type 2 diabetes and coronary artery disease: a prospective study in 2 cohorts of US women and men. The American Journal of Clinical Nutrition, 100(2), 667-675. https://doi.org/10.3945/ajcn.114.084129

Centers for Disease Control and Prevention (CDC). National Center for Health Statistics (NCHS). (2015). National Health and Nutrition Examination Survey Questionnaire (NHANES). Retrieved on March 27, 2020 from CDC Website: https:// wwwn.cdc.gov/Nchs/Nhanes/2015-2016/CBQ_I.htm

Das, J.K., Salam, R.A., Thornburg, K.L., Prentice, A.M., Campisi, S., Lassi, Z.S. and Bhutta, Z.A. (2017). Nutrition in adolescents: physiology, metabolism, and nutritional needs. Annals of the New York Academy of Sciences, 1393(1), 21-33. https:// doi.org/10.1111/nyas. 13330 
Eddyono, F. and Subroto, B. (2014). Purchase Behavior of Noodles: A Case Study of Effort Primary Food Diversification in Indonesia. International Journal of Science and Technology, 3(10).

Fathima, S.J., Nallamuthu, L. and Khanum, F. (2017). Vitamins and minerals fortification using nanotechnology: bioavailability and Recommended Daily Allowances. In Nutrient Delivery, p. 457-496. USA: Academic Press. https://doi.org/10.1016/B978 $-0-12-804304-2.00012-3$

Food and Agriculture Organization (FAO). Food and Human Nutrition. (2004). Retrieved on June 19, 2016 from FAO Website: http://www.fao.org/ rice2004/en/f-sheet/factsheet3.pdf

Hale, J. (2018). The Development of Food Preferences. Retrieved on March 27, 2020 from PsycheCentral website: https://psychcentral.com/lib/thedevelopment-of-food-preferences/

Halim, N.H. and Mohd Yusof, M.M. (2017). Study of Dietary Habits and Nutritional Knowledge among Physical and Health Education (Phe) Students in Uitm Shah Alam. Journal of Research for Education Studies, 1, 1-9.

Harun, R., Ab. Halim, N., Engku Ariff, E.E. and Serin, T. (2018). Consumer Preferences on Malaysia's Specialty Rice presented at the International Seminar on "Promoting Rice Farmers' Market through valueadding Activities", June 6-7, 2018. Thailand: Kasetsart University.

Harvard School of Public Health Nutrition Department (HSPH). (2012). 2012 youth adolescent food frequency questionnaire. Retrieved from Harvard T.H. Chan School of Public Health Nutrition Department's File Download Site: https:// regepi.bwh.harvard.edu/health/KIDS/files

Hawkins, D. and Mothersbaugh, D. (2010). Consumer Behavior: Building Marketing Strategy. $11^{\text {th }}$ ed. New York: McGraw Hill.

Hui-Chin, K.O., Jalil, S.N. and Ruzita, A.T. (2015). Breakfast eating pattern and ready-to-eat cereals consumption among school children in Kuala Lumpur. The Malaysian Journal of Medical Sciences, 22(1), 32-39.

Institute for Public Health (IPH). National Health and Morbidity Survey (NHMS). (2017). Adolescent Nutrition Survey 2017, Malaysia. Retrieved on March 26, 2020 from NHMS website: http:// iku.moh.gov.my/images/IKU/Document/REPORT/ NHMS2017/ANS_KUALALUMPUR.pdf

Keyimu, X.G. (2013). The effects of using seaweed on the quality of Asian noodles. Journal Food Process
Technology, 4(3) 1000216. https:// doi.org/10.4172/2157-7110.1000216

Khor, G.L. (2012). Food availability and the rising obesity prevalence in Malaysia. International $e$ Journal of Science, Medicine and Education, 6(1), 61-68.

Kyrø, C., Tjønneland, A., Overvad, K., Olsen, A. and Landberg, R. (2018). Higher whole-grain intake is associated with lower risk of type 2 diabetes among middle-aged men and women: The Danish Diet, Cancer, and Health Cohort. The Journal of Nutrition, 148(9), 1434-1444. https:// doi.org/10.1093/jn/nxy112

Lateef, O.J., Njogu, E., Kiplamai, F., Haruna, U.S. and Lawal, R.A. (2016). Breakfast, food consumption pattern and nutritional status of students in public secondary schools in Kwara state, Nigeria. Pakistan Journal of Nutrition, 15(2), 140-147. https:// doi.org/10.3923/pjn.2016.140.147

Lipoeto, N.I., Lin, K.G. and Angeles-Agdeppa, I. (2013). Food consumption patterns and nutrition transition in South-East Asia. Public Health Nutrition, 16(9), 1637-1643. https://doi.org/10.1017/ S1368980012004569

Mahan, L.K., Escott-Stump, S., Raymond, J.L. and Krause, M.V. (2012). Krause's Food and the Nutrition Care Process. $13^{\text {th }}$ ed. St. Louis, USA: Elsevier/Saunders.

Mozaffarian, D., Angell, S.Y., Lang, T. and Rivera, J.A. (2018). Role of government policy in nutritionbarriers to and opportunities for healthier eating. The $B M J, 361, \mathrm{k} 2426$. https://doi.org/10.1136/bmj.k2426

Musa, M., Othman, N. and Fatah, F.A. (2011). Determinants of consumers purchasing behaviour for rice in Malaysia. American International Journal of Contemporary Research, 1(3), 159-67.

National Coordinating Committee on Food and Nutrition (NCCFN) (2017). Recommended Nutrient Intakes for Malaysia. A Report of The Technical Working Group on Nutritional Guidelines. Putrajaya, Malaysia: Ministry of Health Malaysia.

Norhayati, M.K., Fairulnizal, M.M., Zaiton, A., Syuriahti, W., Rusidah, S., Aswir, A.R. and Ang, J.L. (2015). Nutritional composition of selected commercial biscuits in Malaysia. Sains Malaysiana, 44(4), 581-591. https:// doi.org/10.17576/jsm-2015-4404-13

Nunnally, J.C. (1994). Psychometric theory 3E. India: Tata McGraw-Hill Education.

Ogundele, O. (2014). Factors influencing consumer's preference for local rice in Nigeria. African Journal 
of Marketing Management, 6(4), 49-55. https:// doi.org/10.5897/AJMM2011.048

Rohman, A., Helmiyati, S., Hapsari, M. and Setyaningrum, D.L. (2014). Rice in health and nutrition. International Food Research Journal, 21 (1), 13-24.

Soon, J.M. and Tee, E.S. (2014). Changing trends in dietary pattern and implications to food and nutrition security in Association of Southeast Asian Nations (ASEAN). International Journal of Nutrition and Food Science, 3(4), 259-269. https:// doi.org/10.11648/j.ijnfs.20140304.15

Supakornchuwong, C. and Suwannaporn, P. (2012). Attitudes toward rice compared with potatoes and pasta among British, French, Dutch and Belgian consumers. Journal of Sensory Studies, 27(2), 71-77. https://doi.org/10.1111/j.1745-459X.2011.00369.x

Thomas, R., Yeoh, T.K., Wan-Nadiah, W.A. and Bhat, R. (2014). Quality evaluation of flat rice noodles (Kway Teow) prepared from Bario and Basmati rice. Sains Malaysiana, 43(3), 339-347.

Vabø, M. and Hansen, H. (2014). The relationship between food preferences and food choice: A theoretical discussion. International Journal of Business and Social Science, 5(7), 145-157. 